\title{
Klaim Rumah Sakit Kepada BPJS Kesehatan Berkaitan Dengan Rawat Inap Dengan Sistem INA- CBGs
}

\author{
Suhartoyo \\ Fakultas Hukum, Universitas Diponegoro \\ J1.Prof.Soedarto, SH Tembalang Semarang \\ suhartoyo@undip.ac.id
}

\begin{abstract}
This study aims to find out the hospital problem for the body organizing the health service (BPJS) with INA-GBGs system. The research method used in this research is normative law research, using a written approach (legal approach), and conceptual approach (conceptual approach), then after that analysis using site analysis. The database analysis base uses primary data and secondary data that allows the author of the data needed directly through the literature and the literature. The results showed that the compilation of the Ministerial Regulation no. 27 of 2014 concerning the basics of the Indonesian case base system and Permenkes No. 28 of 2014 concerning Guidelines for the Implementation of the National Health Insurance Program. This is due to the availability of equipment for the payment of Hospital to BPJS which berorintasi on the frequency of health professions in the Hospital, through the sorting and classification of the hospital.
\end{abstract}

Keywords: hospital claims, BPJS, inpatient With INA-GBGs system

\begin{abstract}
Abstrak
Penelitian ini bertujuan untuk mengetahui pengaturan klaim rumah sakit kepada badan penyelenggaran jaminan soisal (BPJS) kesehatan berkaitan dengan rawat inap dengan sistem INA-GBGs. Metode penelitian yang digunakan dalam penelitian ini adalah penelitian hukum normatif, yang menggunakan pendekatan perundang-undangan (statutory approach), dan pendekatan konseptual (conceptual approach), kemudian setelah itu dianalisis menggunakan analisis sitesis. Basis analisa data menggunakan data primer dan data sekunder yang artinya penulis mencari data-data yang diperlukan secara langsung melalui data kepustakaan dan literatur-literatur. Hasil penelitian menunjukan bahwa pengaturan Permenkes No. 27 Tahun 2014 tentang petunjuk teknis sistem Indonesian Case Base Groups dan Permenkes No. 28 Tahun 2014 tentang Pedoman Pelaksanaan Program Jaminan Kesehatan Nasional telah berjalan berjalan sebagaimana mestinya. Hal tersebut diakibatkan oleh telah tersediannya instrumen teknis petunjuk pelaksanaan pembayaran klaim Rumah Sakit Kepada BPJS yang berorintasi pada perlindungan profesi kesehatan di Rumah sakit, melalui penjenisan dan penggolongan rumah sakit.
\end{abstract}

Kata Kunci: Klaim rumah sakit, BPJS Kesehatan, Rawat Inap Dengan Sistem INA-GBGs

\section{A. Pendahuluan}

Pembiayaan kesehatan merupakan bagianyang penting dalam implementasi Jaminan Kesehatan Nasional (JKN). Menurut Miller (2007) tujuan 
dari pembiayaan kesehatan adalah mendorong peningkatan mutu, mendorong layanan berorientasi pasien, mendorong efisiensi tidak memberikan reward terhadap provider yang melakukan over treatment, undertreatment maupun melakukan adverse event dan mendorong pelayanan tim. Dengan sistem pembiayaan yang tepat diharapkan tujuan diatas bisa tercapai.Terdapat dua metode pembayaran rumah sakit yang digunakan yaitu metode pembayaran retrospektif dan metode pembayaran prospektif.

Metode pembayaran retrospektif adalah metode pembayaran yang dilakukan atas layanan kesehatan yang diberikan kepada pasien berdasar pada setiap aktifitas layanan yang diberikan, semakin banyak layanan kesehatan yang diberikan semakin besarbiaya yang harus dibayarkan. Contoh pola pembayaran retrospektif adalah Fee For Services (FFS). Metode pembayaran prospektif adalah metode pembayaran yang dilakukan atas layanan kesehatan yang besarannya sudah diketahui sebelum pelayanan kesehatan diberikan. Contoh pembayaran prospektif adalah global budget, Perdiem, Kapitasi dan case based payment. Tidak ada satupun sistem pembiayaan yang sempurna, setiap sistem pembiayaan memiliki kelebihan dan kekurangan.

Pilihan sistem pembiayaan tergantung pada kebutuhan dan tujuan dari implementasi pembayaran kesehatan tersebut. Sistem pembiayaan prospektif menjadi pilihan karena: dapat mengendalikan biaya kesehatan; mendorong pelayanan kesehatan tetap bermutu sesuai standar; Pembatas pelayanan kesehatan yang tidak diperlukan berlebihan atau under use; Mempermudah administrasi klaim; dan Mendorong provider untuk melakukan cost containment.

Di Indonesia, metode pembayaran prospektif dikenal dengan Casemix (case based payment) dan sudah diterapkan sejak Tahun 2008 sebagai metode pembayaran pada program Jaminan Kesehatan Masyarakat (Jamkesmas). Sistem casemix adalah pengelompokan diagnosis dan prosedur dengan mengacu pada ciri klinis yang mirip/sama dan penggunaan sumber daya/biaya perawatan yang mirip/sama, pengelompokan dilakukan dengan menggunakan software grouper. Sistem casemix saat ini banyak digunakan sebagai dasar sistem pembayaran kesehatan di negara-negara maju dan sedang dikembangkan di negara-negara berkembang. 
Dalam implementasi Jaminan Kesehatan Nasional (JKN) telah diatur pola pembayaran kepada fasilitas kesehatan tingkat lanjutan adalah dengan INACBGs sesuai dengan Peraturan Presiden Nomor 12 Tahun 2013 tentang Jaminan Kesehatan sebagaimana telah diubah dengan Peraturan Presiden Nomor 111 Tahun 2013. Untuk tarif yang berlaku pada 1 Januari 2014, telah dilakukan penyesuaian dari tarif INA-CBG Jamkesmas dan telah ditetapkan dalam Peraturan Menteri Kesehatan Nomor 69 Tahun 2013 tentang Standar Tarif Pelayanan Kesehatan pada Fasilitas Kesehatan Tingkat Pertama dan Fasilitas Kesehatan Tingkat Lanjutan dalam penyelenggaraan Jaminan Kesehatan.

\section{Permasalahan}

Berdasarkan uraian tersebut diatas maka penelitian ini bertujuan untuk: Pertama, mengetahui bagaimana Pengaturan Pelaksanaan Klaim Rumah Sakit kepada Badan Penyelenggara Jaminan Sosial Kesehatan terkait dengan Rawat Inap dengan sistem INA CBGs. Kedua, bagaimana pula model klaim yang digunakan dalam penyelanggaran Badan Penyelenggara Jaminan Sosial Kesehatan.

\section{Metode Penelitian}

Penelitian merupakan suatu kegiatan ilmiah yang berkaitan dengan analisis dan konstruksi yang dilakukan secara metodologis, sistimatis dan konsisten. Penelitian pada umumnya mengandung dua ciri pokok yaitu logika dan pengamatan empiris. Penelitian dapat dikategorikan dalam beberapa jenis tergantung bagaimana kita melihatnya. Penelitian hukum ditinjau dari sifatya terdiri dari tiga jenis yaitu penelitian eksploratif, penelitian deskripstif dan penelitian eksplanatoris. Ketiga jenis penelitian tersebut dapat dijelaskan sebagai berikut: Petama, Penelitian eksploratif adalah penelitian yang dilakukan apabila pengetahuan tentang sesuatu gejala yang akan diselidiki masih kurang sekali atau bahkan tidak ada. Kedua, Penelitian deskriptif adalah penelitian yang dimaksudkan untuk memberikan data seteliti mungkin tentang manusia, keadaan, atau gejala-gejala lainya. Ketiga, Penelitian eksplanatoris adalah penelitian yang dimaksudkan untuk menguji hiposa-hipotesa tertentu.

Penelitian dengan judul " Pelaksanaan Klaim Rumah Sakit kepada Badan Penyelenggara Jaminan Sosial Kesehatan terkait dengan Rawat Inap dengan sistem INA CBGs." Merupakan penelitian hukum normatif dan hukum empiris yaitu penelitian yang dilakukan dengan mengumpulkan bahan hukum 
baik primer, sekunder, dan atau tersier. Dalam rangka mendapatkan jawaban atau penyelesaian atas masalah-masalah (isu hukum) yang telah dirumuskan, dapat dipergunakan empat model pendekatan penyelesaian masalah yaitu pendekatan peraturan perundang-undangan (statutory approach), pendekatan konseptual (conseptual approach), pendekatan komparatif (comparative approach), dan pendekatan historis (historical approach), yang penerapannya disesuaikan dengan kebutuhan.

\section{B. Hasil Penelitian Dan Pembahasan}

Hasil penelitian tentang "Klaim Rumah Sakit Kepada Badan penyelenggaran jaminan soisal (BPJS) Kesehatan Berkaitan dengan Rawat Inap Dengan Sistem INA-GBGs" ini akan dijelaskan dengan dua poin utama yaitu 1). Pengaturan Pelaksanaan Klaim Rumah Sakit kepada Badan Penyelenggara Jaminan Sosial Kesehatan terkait dengan Rawat Inap dengan sistem INA CBGs. 2). Model klaim yang digunakan dalam penyelanggaran Badan Penyelenggara Jaminan Sosial Kesehatan. Adapun penjelasannya adalah sebagai berikut:

1. Pengaturan Pelaksanaan Klaim Rumah Sakit kepada Badan Penyelenggara Jaminan Sosial Kesehatan Rawat Inap dengan sistem INA CBGs.

Secara umum pelasaksanaan pelaksanaan klaim rumah sakit kepada BPJS berdsarkan pada peraturan perundang undangan sebagai berikut: 1).Undang-Undang Nomor 40 Tahun 2004 tentang Sistem Jaminan Sosial Nasional; 2). Undang-Undang Nomor 24 Tahun 2011 tentang Badan Penyelenggara Jaminan Sosial, 3). Peraturan Presiden Nomor 12 Tahun 2013 tentang Jaminan Kesehatan, 4). Peraturan Menteri Kesehatan Nomor 69 Tahun 2013 tentang Standar Tarif Pelayanan Kesehatan pada Fasilitas Kesehatan Tingkat Pertama dan Fasilitas Kesehatan Tingkat Lanjutan dalam penyelenggaraan Jaminan Kesehatan, dan 5). Peraturan Menteri Kesehatan Nomor 71 Tahun 2013 Tentang Pelayanan Kesehatan Pada Jaminan Kesehatan Nasional.

Berdasarkan Pasal 5 ayat (3) Undang-Undang No. 40 Tahun 2004 tentang Sistem Jaminan Sosial Nasional menyebutkan bahwa bahwa Badan penyelenggara Jaminan Sosial ( BPJS ) merupakan pengganti program jaminan 
Sosial yang telah ada sebelumnya yaitu Perusahaan Perseroan (Persero) Jaminan Sosial Tenaga Kerja (JAMSOSTEK), Perusahaan Perseroan (Persero) Dana Tabungan dan Asuransi Pegawai Negeri (TASPEN), Perusahaan Perseroan ( Persero ) Asuransi Sosial Angkatan Bersenjata Republik Indonesia (ASABRI) serta Perusahaan Perseroan (Persero) Asuransi Kesehatan Indonesia (ASKES).

Dalam menjalankan Program Jaminan Kesehatan Nasional pihak BPJS Kesehatan menggandeng beberapa rumah sakit milik pemerintah maupun rumah sakit swasta. Berdasarkan Pasal 4 Peraturan Menteri Kesehatan Nomor 71 Tahun 2013 menjelaskan bahwa perjanian kerjasama fasilitas kesehatan dengan BPJS Kesehatan dilakukan antara pimpinan atau pemilik fasilitas kesehatan yang berwenang dengan BPJS Kesehatan. Pelaksanaan pada umumnya semua jenis rumah sakit yang ada di Seluruh Indonesia baik rumah sakit pemerintah, swasta, mapun rumah sakit jenis lainnya. Pada saat ini pemerintah melakukan pembayar melalui sistem. Paling tidak dikenal ada dua metode yang dugunakan oleh pemerintah. Metode pembayaran prospektif adalah metode pembayaran yang dilakukan atas layanan kesehatan yang besarannya sudah diketahui sebelum pelayanan kesehatan diberikan. Contoh pembayaran prospektif adalah global budget, Perdiem, Kapitasi dan case based payment. Tidak ada satupun sistem pembiayaan yang sempurna, setiap sistem pembiayaan memiliki kelebihan dan kekurangan.

Pilihan sistem pembiayaan tergantung pada kebutuhan dan tujuan dari implementasi pembayaran kesehatan tersebut. Sistem pembiayaan prospektif menjadi pilihan karena: dapat mengendalikan biaya kesehatan; mendorong pelayanan kesehatan tetap bermutu sesuai standar; Pembatas pelayanan kesehatan yang tidak diperlukan berlebihan atau under use; Mempermudah administrasi klaim; dan Mendorong provider untuk melakukan cost containment.

Di Indonesia, metode pembayaran prospektif dikenal dengan Casemix (case based payment) dan sudah diterapkan sejak Tahun 2008 sebagai metode pembayaran pada program Jaminan Kesehatan Masyarakat (Jamkesmas). Sistem casemix adalah pengelompokan diagnosis dan prosedur dengan 
mengacu pada ciri klinis yang mirip/sama dan penggunaan sumber daya/biaya perawatan yang mirip/sama, pengelompokan dilakukan dengan menggunakan software grouper. Sistem casemix saat ini banyak digunakan sebagai dasar sistem pembayaran kesehatan di negara-negara maju dan sedang dikembangkan di negara-negara berkembang.

Berdasarkan Bab IV huruf C Peraturan Menteri Kesehatan Nomor 28 Tahun 2014 tentang Pedoman Pelaksanaan Program Jaminan Kesehatan Nasional menjelaskan bahwa ada beberapa fasilitas dan pelayanan kesehatan yang dijamin dan yang tidak dijamin oleh BPJS kesehatan antara lain :

a. Fasilitas dan Pelayanan Kesehatan yang Dijamin :

1) Administrasi pelayanan.

2) Pemeriksaan, pengobatan dan konsultasi spesialistik oleh dokter spesialis dan sub spesialis.

3) Tindakan medik spesialistik, baik bedah maupun non bedah sesuai dengan indikasi medis.

4) Pelayanan obat dan bahan medis habis pakai.

5) Pelayanan penunjang diagnostik lanjutan sesuai dengan indikasi medis.

6) Rehabilitasi medik.

7) Pelayanan darah.

8) Pelayanan kedokteran forensik klinik.

9) Pelayanan jenazah ( pemularasan jenazah ) pada pasien yang meninggal di fasilitas kesehatan ( tidak termasuk peti jenazah )

10) Perawatan inap non - intensif.

11) Perawatan inap di ruang intensif

12) Akupuntur medis.

Manfaat atau fasilitas pelayanan promotif dan preventif meliputi :

1) Penyuluhan kesehatan perorangan, meliputi paling sedikit penyuluhan mengenai pengelolaan faktor risiko penyakit dan perilaku hidup bersih dan sehat.

2) Imunisasi dasar, meliputi Baccile Calment Guerin ( BCG ), Difteri Pertusis Tetanus dan Hepatitis-B (DPT-HB), Polio dan Campak. 
3) Keluarga berencana, meliputi konseling, kontrasepsi dasar, vasektomi, tubektomi, termasuk komplikasi KB bekerja sama dengan lembaga yang membidangi keluarga berencana.

4) Vaksin untuk imunisasi dasar dan alat kontrasepsi dasar disediakan oleh Pemerintah dan/atau Pemerintah Daerah

5) Pelayananan skrining kesehatan tertentu diberikan secara selektif untuk mendeteksi risiko penyakit dan mencegah dampak lanjutan, yaitu: Diabetes Mellitus tipe II; Hipertensi; Kenker Leher Rahim; Kanker Payudara; Penyeakit lain yang ditetapkan Menteri

6) Pelayanan Skrining kesehatan tertentu dalam poin (5) merupakan pelayanan yang termasuk dalam lingkup non-kapitasi, yang dilaksanakan sesuai dengan ketentuan Peraturan Perundang - Undangan. Pemeriksaan penunjang pelayanan skrinning kesehatan meliputi: Pemeriksaan Gula Darah; Pemeriksaan IVA untuk kasus Ca Cervix; Pemeriksaan Pap Smear

7) Khusus untuk kasus dengan pemeriksaan IVA positif dapat dilakukan pelayanan Terapi Krio.

\section{Sistim INA - CBGs}

INA - CBGs ( Indonesia Case Base Groups ) merupakan sistim dimana besaran pembayaran klaim oleh BPJS Kesehatan kepada fasilitas kesehatan rujukan tingkat lanjutan yang merupakan sistim kodifikasi dari diagnosis akhir dan tindakan atau prosedur yang menjadi output pelayanan yang mengacu pada Internatonal Code Diseases Ten ( ICD 10 ) dan International Code Diseases Nine ( ICD 9 ) Clinical Modification ( CM ) yang disusun oleh World Healt Organization ( WHO ). Berdasarkan Peraturan Menteri Kesehatan Nomor 27 Tahun 2014 tentang Petunjuk Teknis Sistem Indonesian Case Base Groups ( INA - CBGs ) menyatakan bahwa INA CBGs merupakan salah satu perangkat entry data pasien yang digunakan untuk melakukan grouping tarif berdasarkan data yang berasal dari resume medis. Untuk menggunakan aplikasi INA - CBGs, rumah sakit harus memiliki kode registrasi rumah sakit yang dikeluarkan oleh Direktorat Jendral Bina Upaya Kesehatan dan selanjutnya dilakukan aktifasi bagi setiap rumah sakit sesuai dengan kelas rumah sakit serta regionalisasinya. 


\section{Apa Saja yang Sebaiknya Dilakukan dan Tidak Dilakukan Rumah} Sakit

Berdasarkan Bab V Peraturan Menteri Kesehatan Nomor 27 Tahun 2014 tentang Petunjuk Teknis Sistem Indonesian Case Base Groups ( INACBGs ) menjelaskan bahwa pihak rumah sakit harus memperhatikan upaya apa saja yang sebaiknya dilakukan rumah sakit dan apa saja yang sebaiknya tidak dilakukan oleh rumah sakit dalam menjalankan klaim dengan BPJS kesehatan antara lain :

a. Upaya yang sebaiknya dilakukan rumah sakit :

1) Membangun tim rumah sakit

Manajemen dan profesi serta komponen rumah sakit yang lain harus mempunyai persepsi dan komitmen yang sama serta mampu bekerja sama untuk menghasilkan produk pelayanan rumah sakit yang bermutu dan cost efective. Bukan sekedar untuk mencari keuntungan sebesar-besarnya. Sebagai tim semua komponen rumah sakit harus memahami tentang konsep tarif paket, dimana dimungkinkan suatu kasus atau kelompok CBG tertentu mempunyai selisih positif dan pada kasus atau kelompok kasus CBG yang sama pada pasien berbeda ataupun pada kelompok CBG lain mempunyai selisih negatif. Surplus atau selisih positip pada suatu kasus atau kelompok CBG dapat digunakan untuk menutup selisih negatif pada kasus lain atau kelompok CBG lain (subsidi silang). Sehingga pelayanan rumah sakit tetap mengedepankan mutu pelayanan dan keselamatan pasien.

2) Meningkatkan efisiensi

Efisiensi tidak hanya dilakukan pada sisi proses seperti penggunaan sumber daya farmasi, alat medik habis pakai, lama rawat, pemeriksaan penunjang yang umumnya menjadi area profesi tetapi juga pada sisi input seperti perencanaan dan pengadaan barang dan jasa yang umumnya menjadi area/tanggung jawab menejemen. Sisi proses umumnya lebih menekankan pada aspek efektifitas sedangkan sisi input umumnya lebih menekankan aspek efisiensi. Keduanya harus mampu berinteraksi untuk menghasilkan produk pelayanan yang cost effective. Sisi proses dalam hal melakukan efisiensi juga harus mampu mengurangi atau bahkan 
menghilangkan pelayanan yang berlebih dan tidak diperlukan (over treatment dan atau over utility). Seperti penggunaan/pemilihan obat yang berlebihan dan pemeriksaan penunjang yang tidak selektif dan tidak kuat indikasinya. Efisiensi juga harus dilakukan pada biaya umum seperti penggunaan listrik, air, perlengkapan kantor dan lain-lain. Inefisiensi pada sisi input maupun proses akan berpengaruh pada ongkos/biaya produksi pelayanan rumah sakit yang mahal.

3) Memperbaiki mutu rekam medis

Tarif INA-CBGs sangat ditentukan oleh output pelayanan yang tergambar pada diagnosis akhir (baik diagnosis utama maupun diagnosis sekunder) dan prosedur yang telah dilakukan selama proses perawatan. Kelengkapan dan mutu dokumen rekam medis akan sangat berpengaruh pada koding, grouping dan tarif INA-CBGs.

4) Memperbaiki kecepatan dan mutu klaim

Kecepatan dan mutu klaim akan mempengaruhi cash flow rumah sakit. Kecepatan klaim sangat dipengaruhi oleh kecepatan penyelesaian berkas rekam medis. Sehingga rumah sakit harus menata sistem pelayanan rekam medis yang baik agar kecepatan dan mutu rekam medis bisa memperbaiki dan meningkatkan cash flow rumah sakit.

5) Melakukan standarisasi

Perlu terus dibangun standard input dan proses di tingkat rumah sakit. Standard input misalnya farmasi, alat medik habis pakai . Perlu dibuat formularium rumah sakit (perencanaan), perlu dibuat standar pengadaan obat rumah sakit (e katalog dan atau lelang), standar penulisan resep misal dokter hanya menulis nama generik sedangkan obat yang diberikan berdasar hasil/perolehan pengadaan. Standar proses misalnya PPK/SPO dan atau clinical pathway. Keputusan/penetapan standar proses akan sangat berpengaruh pada pembuatan keputusan pada standar input.

6) Membentuk Tim Casemix/Tim INA-CBG rumah sakit Tim Casemix/Tim INA-CBGs rumah sakit akan menjadi penggerak membantu melakukan sosialisasi, monitoring dan evaluasi implementasi INA-CBGs di rumah sakit.

7) Memanfaatkan data klaim. 
Data INA-CBGs rumah sakit dapat digunakan/dimanfaatkan tidak hanya untuk klaim tetapi juga dapat digunakan untuk menilai performance rumah sakit dan performance SDM khususnya profesi dokter. Data INA-CBGs bisa juga digabungkan dengan data HIMS (Health Information Management System) bahkan bisa dibandingkan dengan rumah sakit lain yang sekelas. Jadi data INA-CBGs dan data klaim dapat digunakan sebagai bahan untuk pengambilan keputusan/kebijakan tingkat rumah sakit.

8) Melakukan reviu post-claim

Reviu post-claim yang dilakukan secara berkala sangat penting dalam menentukan kebijakan yang berkaitan dengan pengendalian biaya dan mutu dalam pelayanan yang akan diberikan. Idealnya kegiatan reviu ini melibatkan seluruh unit yang ada di rumah sakit baik manajemen, tenaga professional, serta unit penunjang maupun pendukung dan dilakukan dengan data yang telah dianalisis oleh tim Casemix rumah sakit.

9) Pembayaran jasa medis

Perubahan metode pembayaran rumah sakit dengan metode paket INACBGs sebaiknya diikuti dengan perubahan pada cara pembayaran jasa medis. Pembayaran jasa medis sebaiknya disesuaikan dengan menggunakan sistem remunerasi berbasis kinerja.

10) Untuk masa yang akan datang diharapkan seluruh rumah sakit provider JKN bisa berkontribusi untuk mengirimkan data koding dan data costing sehingga dapat dihasilkan tarif yang mencerminkan actual cost pelayanan di rumah sakit.

b. Apa saja yang sebaiknya tidak dilakukan oleh pihak rumah sakit.

Implementasi INA-CBG sebaiknya dilakukan dengan benar dan penuh tanggunggung jawab dari semua pihak. Sebaiknya rumah sakit tidak melakukan hal hal dibawah ini :

1) Merubah atau membongkar software

2) Menambah diagnosis yang tidak ada pada pasien yang diberikan pelayanan untuk tujuan meningkatkan tingkat keparahan atau untuk tujuan mendapatkan grouping pada kelompok tariff yang lebih besar. 
3) Menambah prosedur yang tidak dilakukan atau tidak ada bukti pemeriksaan untuk tujuan mendapatkan grouping pada kelompok tariff yang lebih besar.

4) Melakukan input diagnosis dan prosedur hingga proses grouping berkali-kali dengan tujuan mendapatkan kelompok tarif yang lebih besar.

5) Upcoding, yaitu memberikan koding dengan sengaja dengan tujuan meningkatkan pembayaran ke rumah sakit.

6) Melakukan manipulasi terhadap diagnosis dengan menaikkan tingkatan jenis tindakan. Misalnya : appendiectomy tanpa komplikasi ditagihkan sebagai appendiectomy dengan komplikasi, yang memerlukan operasi besar sehingga menagihkan dengan tarif yang lebih tinggi.

7) Memberikan pelayanan dengan mutu yang kurang baik. Misalnya: memperpendek jam pelayanan poliklinik, pelayanan yang bisa diselesaikan dalam waktu satu hari dilakukan pada hari yang berbeda, tidak melakukan pemeriksaan penunjang yang seharusnya dilakukan, tidak memberikan obat yang seharusnya diberikan, serta membatasi jumlah tempat tidur yang tersedia di rumah sakit untuk peserta JKN.

\section{Model klaim yang digunakan dalam penyelanggaran Badan Penyelenggara Jaminan Sosial Kesehatan}

Sistem casemix pertama kali dikembangkan di Indonesia pada Tahun 2006 dengan nama INA-DRG (Indonesia- Diagnosis Related Group). Implementasi pembayaran dengan INA-DRG dimulai pada 1 September 2008 pada 15 rumah sakit vertikal, dan pada 1 Januari 2009 diperluas pada seluruh rumah sakit yang bekerja sama untuk program Jamkesmas.

Pada tanggal 31 September 2010 dilakukan perubahan nomenklatur dari INA-DRG (Indonesia Diagnosis Related Group) menjadi INA-CBG (Indonesia Case Based Group) seiring dengan perubahan grouper dari 3M Grouper ke UNU (United Nation University) Grouper. Dengan demikian, sejak bulan Oktober 2010 sampai Desember 2013, pembayaran kepada Pemberi Pelayanan Kesehatan (PPK) Lanjutan dalam Jaminan kesehatan masyarakat (Jamkesmas) menggunakan INA-CBG. Sejak 
diimplementasikannya sistem casemix di Indonesia telah dihasilkan 3 kali perubahan besaran tarif, yaitu tarif INA-DRG Tahun 2008, tarif INA-CBG Tahun 2013 dan tarif INA-CBG Tahun 2014. Tarif INA-CBG mempunyai 1.077 kelompok tarif terdiri dari 789 kode grup/kelompok rawat inap dan 288 kode grup/kelompok rawat jalan, menggunakan sistem koding dengan ICD-10 untuk diagnosis serta ICD-9-CM untuk prosedur/tindakan. Pengelompokan kode diagnosis dan prosedur dilakukan dengan menggunakan grouper UNU (UNU Grouper). UNU- Grouper adalah Grouper casemix yang dikembangkan oleh United Nations University (UNU).

\section{Tarif INA-CBGs Dalam Jaminan Kesehatan Nasional}

Tarif INA-CBGs yang digunakan dalam program Jaminan Kesehatan Nasional (JKN) per 1 Januari 2014 diberlakukan berdasarkan Peraturan Menteri Kesehatan, dengan beberapa prinsip sebagai berikut :

1. Pengelompokan Tarif 7 kluster rumah sakit, yaitu : Tarif Rumah Sakit Kelas A; Tarif Rumah Sakit Kelas B; Tarif Rumah Sakit Kelas B Pendidikan; Tarif Rumah Sakit Kelas C; Tarif Rumah Sakit Kelas D; Tarif Rumah Sakit Khusus Rujukan Nasional; Tarif Rumah Sakit Umum Rujukan Nasional. Pengelompokan tarif berdasarkan penyesuaian setelah melihat besaran Hospital Base Rate (HBR) sakit yang didapatkan dari perhitungan total biaya pengeluaran rumah sakit. Apabila dalam satu kelompok terdapat lebih dari satu rumah sakit, maka digunakan Mean Base Rate.

2. Regionalisasi, tarif terbagi atas 5 Regional yang didasarkan pada Indeks Harga Konsumen (IHK) dan telah disepakati bersama antara BPJS Kesehatan dengan Asosiasi Fasilitas Kesehatan Tingkat Lanjutan

3. Terdapat pembayaran tambahan (Top Up) dalam sistem INA-CBGs versi 4.0 untuk kasus - kasus tertentu yang masuk dalam special casemix main group (CMG) ,meliputi : Special Prosedure; Special Drugs; Special Investigation; Special Prosthesis; Special Groups Subacute dan Kronis.

4. Top up pada special CMG tidak diberikan untuk seluruh kasus atau kondisi, tetapi hanya diberikan pada kasus dan kondisi tertentu. Khususnya pada beberapa kasus atau kondisi dimana rasio antara tarif INA-CBGs yang sudah dibuat berbeda cukup besar dengan tarif RS. Penjelasan lebih rinci tentang Top Up dapat dilihat pada poin D. 
5. Tidak ada perbedaan tarif antara rumah sakit umum dan khusus, disesuaikan dengan penetapan kelas yang dimiliki untuk semua pelayanan di rumah sakit berdasarkan surat keputusan penetapan kelas yang dikeluarkan oleh Kementerian Kesehatan RI.

6. Tarif INA-CBGs merupakan tarif paket yang meliputi seluruh komponen sumber daya rumah sakit yang digunakan dalam pelayanan baik medis maupun non-medis.

Untuk Rumah Sakit yang belum memiliki penetapan kelas, maka tarif INACBGs yang digunakan setara dengan Tarif Rumah Sakit Kelas D sesuai regionalisasi masing-masing.

Penghitungan tarif INA CBGs berbasis pada data costing dan data koding rumah sakit. Data costing didapatkan dari rumah sakit terpilih (rumah sakit sampel) representasi dari kelas rumah sakit, jenis rumah sakit maupun kepemilikan rumah sakit (rumah sakit swasta dan pemerintah), meliputi seluruh data biaya yang dikeluarkan oleh rumah sakit, tidak termasuk obat yang sumber pembiayaannya dari program pemerintah (HIV, TB, dan lainnya). Data koding diperoleh dari data koding rumah sakit PPK Jamkesmas. Untuk penyusunan tarif JKN digunakan data costing 137 rumah sakit pemerintah dan swasta serta 6 juta data koding (kasus).

Peraturan Presiden Nomor 12 Tahun 2013 tentang Jaminan Kesehatan sebagaimana telah diubah dengan Peraturan Presiden Nomor 111 Tahun 2013, mengamanatkan tarif ditinjau sekurang-kurangnya setiap 2 (dua) tahun. Upaya peninjauan tarif dimaksudkan untuk mendorong agar tarif makin merefleksikan actual cost dari pelayanan yang telah diberikan rumah sakit. Selain itu untuk meningkatkan keberlangsungan sistem pentarifan yang berlaku, mampu mendukung kebutuhan medis yang diperlukan dan dapat memberikan reward terhadap rumah sakit yang memberikan pelayanan dengan outcome yang baik. Untuk itu keterlibatan rumah sakit dalam pengumpulan data koding dan data costing yang lengkap dan akurat sangat diperlukan dalam proses updating tarif.

\section{Kesimpulan}

Berdasarkan kseluruhan uraian tersebut maka penelitian ini dapat disimpulkan bahwa pengaturan Permenkes No. 27 Tahun 2014 tentang petunjuk teknis sistem Indonesian Case Base Groups dan Permenkes No. 28 Tahun 2014 tentang Pedoman Pelaksanaan Program Jaminan Kesehatan Nasional telah berjalan berjalan sebagaimana 
mestinya. Hal tersebut diakibatkan oleh telah tersediannya instrumen teknis petunjuk pelaksanaan pembayaran klaim Rumah Sakit Kepada BPJS yang berorintasi pada perlindungan profesi kesehatan di Rumah sakit, melalui penjenisan dan penggolongan rumah sakit.

\section{Daftar Pustaka}

Busro, Achmad, 2012,Hukum Perikatan Berdasar Buku III KUH Perdata, Yogyakarta, Pohon Cahaya

Hartono, Sri Rejeki, 1997, Hukum Asuransi dan Perusahaan Asuransi, Jakarta, Sinar Grafika Offset

Junaedy, A. Ganie, 2011, Hukum Asuransi Indonesia, Jakarta, Sinar Grafika.

Mulyadi, Kartini dan Gunawan Wijaya, 2002, Perikatan Yang Lahir Dari Perjanjian, PT. Raja Grafindo Persada

Notoadmodjo, Soekidjo, 2010, Etika \& Hukum Kesehatan, Jakarta, Rineka Cipta

Nasution, S, 2013, Metode Penelitian Naturalistik Kualitatif, Bandung, Tarsito

Salim, A.Abbas,1993, Dasar - Dasar Asuransi, Jakarta, PT. Raja Grafindo Persada.

S, Kertonegoro, 1999, Hukum Asuransi Indonesia, PT. Citra Aditya Bakti., Bandung.

Subekti, 2004, Hukum Perjanjian, Jakarta, PT Intermasa.

Thabrany, Hasbullah, 2004, Hukum Perjanjian, Jakarta, PT Intermasa.

Yustina, Endang Wahyati, Mengenal Hukum Rumah Sakit, Bandung : CV Keni Media.

Undang - Undang Nomor 40 Tahun 2004 Tentang Sistem Jaminan Sosial Nasional

Undang - Undang Nomor 24 Tahun 2011 Tentang Badan Penyelenggara Jaminan Sosial

Peraturan Menteri Kesehatan Nomor 69 Tahun 2013 Tentang Standart Tarif Pelayanan Kesehatan Pada Fasilitas Kesehatan Tingkat Pertama dan Fasilitas Kesehatan Tingkat Lanjut dalam penyelenggaraan Jaminan kesehatan

Peraturan Menteri Kesehatan Nomor 27 Tahun 2014 Tentang Petunjuk Teknis Sistem Indonesian Case Base Groups ( INA - CBGs ).

Peraturan Menteri Kesehatan Nomor 28 Tahun 2014 Tentang Pedoman Pelaksanaan Program Jaminan Kesehatan Nasional. 